\title{
The Essential Role of HRM in Managing Talent and Workforce in Global Business Services (GBS) Firm
}

\section{Rosmelisa Yusof \& Chang Seng Loong}

To Link this Article: http://dx.doi.org/10.6007/IJARBSS/v11-i9/10831

DOI:10.6007/IJARBSS/v11-i9/10831

Received: 12 July 2021, Revised: 30 July 2021, Accepted: 17 August 2021

Published Online: 26 September 2021

In-Text Citation: (Yusof \& Loong, 2021)

To Cite this Article: Yusof, R., \& Loong, C. S. (2021). The Essential Role of HRM in Managing Talent and Workforce in Global Business Services (GBS) Firm. International Journal of Academic Research in Business and Social Sciences, 11(9), 1756-1763.

\section{Copyright: (c) 2021 The Author(s)}

Published by Human Resource Management Academic Research Society (www.hrmars.com)

This article is published under the Creative Commons Attribution (CC BY 4.0) license. Anyone may reproduce, distribute, translate and create derivative works of this article (for both commercial and non-commercial purposes), subject to full attribution to the original publication and authors. The full terms of this license may be seen

at: http://creativecommons.org/licences/by/4.0/legalcode

Vol. 11, No. 9, 2021, Pg. 1756 - 1763

Full Terms \& Conditions of access and use can be found at http://hrmars.com/index.php/pages/detail/publication-ethics 


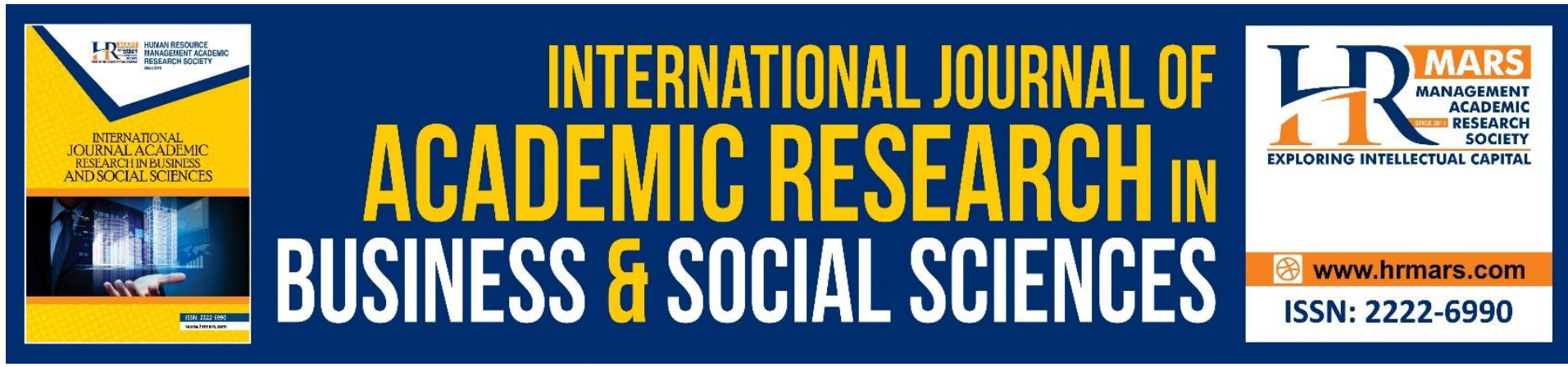

\title{
The Essential Role of HRM in Managing Talent and Workforce in Global Business Services (GBS) Firm
}

\author{
Rosmelisa Yusof \& Chang Seng Loong \\ School of Management, Universiti Sains Malaysia
}

\begin{abstract}
This article discusses on how companies in a global business services sector recruit and manage their talent and workforce. This study focus on several criteria that contribute to managing talent and workforce in a company from services sector. Using a qualitative method, data were collected through in-depth interviews with employees who are working in companies specialising in global services sector. Content analysis was analyzed for categorization, summarization and coding of the data. The study found that planning, recruitment and selection, and retention were significant for GBS firm to manage and retain their talent and workforce. The results suggest that GBS firm can be further enhance their talent and workforce via various strategy of retention.
\end{abstract}

Keywords: GBS, Talent and Workforce, HR Planning, Recruitment and Selection, Employee Retention

\section{Introduction}

Services sector has transformed tremendously in these few decades and expanding at a fastest rate in various countries worldwide. The fast spread of business globally has led to the global expansion of companies (Sun \& Pang, 2017). This expansion covered the product oriented business and services companies (Hitt et al., 2006). Globally, the trend of services are moving towards shared services and outsourcing for the last two decades. Shared services was known as a service that handled by one part of an organization only while outsourcing related to the firm switching their internal input to source it out to other contractor or independent suppliers (Sako, 2015). The services sector in Malaysia contributed more than 50 per cent of the national GDP whereby these services sector employed around two million people and the number keep increasing every year (NST, 2019).

Due to fast pace of technology development, services sector now has expanded towards global business services. The shared services provided by the firm nowadays not just limited to one place only but covering services throughout the world. This type of services are widely known as Global Business Services (GBS). As far as GBS is concerned, the business services provided by GBS are referring to providing professional services to other companies or businesses rather than providing it to the end consumer (Wirtz, Tuzovic \& Ehret, 2015). The 
GBS provides various services that are widely range depending on the need of the business's companies.

The GBS firm provides the services demanded by any companies around the world. The GBS firm provides the services demanded by any companies around the world. Therefore, GBS firm must attract and retain the best employees in their organization in order to to meet the demand from their client. This has become one of the challenges task to the company. Thus, the GBS organization must enhance the role of Human Resource Management by having a systematic process of hiring and retaining their talent and workforce.

\section{Literature Review \\ Global Business Services (GBS)}

GBS is a new business models that offer services to other companies by using innovation, skill and expertise of their employees across the globe. The main concept of this services sector is by having the idea of openness of services and they need to face the challenge such as cultural difference, language, geographic distance. (Manning et al., 2015). The new trend of GBS introduced the role of international service trade whereby the mass usage of advanced information and communication technology was applied by the service sectors (Eichengreen \& Gupta, 2012). These practices therefore have led to the services being provided globally as there is no limitation of boundaries.

Huggins and Thompson (2015) mentioned that the increasing trends of GBS includes the factor such as sharing of knowledge and also foster innovation. Mostly, GBS firms are having the concept of "open innovation" in order for them to manage the inflows and outflows of knowledge by maximizing their external exploitation of other countries and thereafter enhancing their internal innovation. (Cheng and Shiu, 2015; Chesbrough, 2003). Thus, the current trends of GBS provides growing interest for outsourcing, organizational agility, collaboration, offshoring and flexibility to increase the network throughout the world. (Huggins and Thompson, 2015).

GBS has become the key factors in economic transformation for many countries and Malaysia is part of it. Malaysia is now moving forwards to become one of the world-class international GBS hub (Wei, Thurasamy \& Popa, 2017). As we can see Malaysia was deem as one of the global GBS player since that provide various international services. Malaysian government provided support to GBS through Multimedia Super Corridor (MSC) project by offering financial aids in term of developing modern telecommunication infrastructures, information technology and communication technologies (ICT). Apart from that, Malaysian government also provide various incentives and tax exemption for international GBS company to be set up in Malaysia. By that, GBS contributes a larger number of total export sales, total employment opportunity for knowledge workers and gross domestic product of Malaysia (Lee, 2017). According to Lee (2017), the GBS in Malaysia has recorded an increase from 10 to 15 percent for several past years since 2011. Thus, GBS sector are seen as one the promising sector that provides plenty of benefit to the development of a country.

\section{Talent and Workforce}

Talent and workforce are one the valuable resources for a company. In organization, the task to maximize the talent and workforce is needed for the management to plan the work flow of the organization. Most of the time, the talent management was handled by the human resource management. Talent management dealing with a wider range of human resource activities such as attracting, selecting, developing and retaining the best employees 
in their company to remain the talent (CIPD, 2006). In addition, if all the company could enhance and scrutinize their employees' talents and skills, it will be a key factor for the business to achieve their objectives. (Michaels et al., 2001)

In this era of globalization, the attracting and retaining the best employees becoming one of the challenges task to the company. The organisation must invest in hiring good employee as a way to settle specific problem (Lyons and Marler, 2001). Besides that, the competition between the company in recruiting the talent becoming the phenomenon recently. This is because the great and skillful talent becoming the key factor for the company to gain their competitive advantage against their rivals (Greening and Turban, 2000). In meantime, Cheese (2008) suggest that organization must be able to discover the ability and diversity of their talent as part of the organization to be competitive.

Besides that, Cheese (2008) also provides another strategy of transforming human resource as a way to strengthen the talent management. The transforming human resource includes harmonized process and polices, integrated human resource systems and information, shared services and focused, and improved capabilities and governance. These four ways is crucial in order to ensure the management is efficient and effective in term of managing human resource capability. This is because to increase the human resource capabilities by improving the function, capabilities and value-added of the talent is one of the tools to sustain their production in every department in the company.

\section{Recruitment, Selection and Retention}

Recruitment of talents are defined as locating, identifying and attracting capable applicants (Kinicki \& Williams, 2019). The definition of selection is screening job applicants to ensure that the most appropriate candidates are hired (Robbins \& Coulter, 2014). The important features of recruitment that management is looking forwards on the candidate are behaviors, attitude, skills and preference (Davenport et al., 2010). Apart from that, organization need to match their current need and expectation of the employees (Pandita \& Ray, 2018).

Retention can be defined as the encouragement provided by the firm in order to ensure the employees remain with the firm for a longer period of time (Das, 2013). As such, the organization will make a proper planning for retaining their employee as a way to stop their employee to quit. Organization keep on facing the challenges of retaining their talented and skillful employees (Bibi et al, 2017). Walker (2001) stated that the task of retaining good employee is crucial and necessary for a an organization as one of their strategy to be competitive. Moreover, the cost of recruitment and negative impact of employees leaving the organization has made the role of retention is deem as important for the organization (Pandita \& Ray, 2018). Kundu and Lata (2017) stated various factor that encourage employee retention such as work-life balance, communication, compensation and benefit, learning culture, recognition and positive relationship surrounding the organization. As such, firms need to plan and make a strategy on providing positive support and preparing good working environment for employees.

\section{Methodology}

This study employed a qualitative method that using purposive sampling. Apart from that, this study employed a triangulation technique in order to establish validity and credibility of data (Riege, 2003). As such, this study used multiples sources of evidence such as in-depth interview session, observation and documents reviewed. The unit of analysis of this study 
were employees working in GBS company. Seven key informants among employees who works in GBS company in Malaysia were selected as the participants for this study. The indepth interview session were conducted with each of the employees in their workplace and each of the session lasted for 30 to 40 minutes. The interview questions was prepared based on the main issues related to human resource management process. The session was recorded and the interviews were transcribed. The transcribed data was then subjected to content analysis in order to code, categorize and synthesize (Erlingson \& Brysiewicz, 2017).

\section{Results}

This research is focusing on the talent and mangament practices of GBS company in Malaysia. GBS firms are based in few states surrounding peninsular Malaysia mainly based in Kuala Lumpur, Selangor, Penang and Perak. These GBS companies provides various range of professional services such as finance, human resources, information technology and many more of related services. For example in one of the GBS firm, the services provided by them are categorized as functional departmentalization that include purchasing department, payroll department, human resource department and so on. Every department has different key performance indicator for each employee and department.

The employees in GBS firm are assign base on task and end result instead of working hour. Therefore, the employees in most GBS firm are working with flexible working hour which is based on their daily process and daily task. For example in one of the GBS firm, they have a two working shift which are day shift and night shift due to different time zone with their international client. In addition, the employees will be given some benefit such as shift allowance and seasonal parking if they are working night shift. Besides that, the language allowance will be given if they know some specific language.

\section{Recruitment and Selection}

The recruitment and selection process of GBS firm are handled by the HR management. The recruitment of new employees in GBS firm are depends on the available position. Most of the time, the company need to hire new employees due to resignation of former employees.

"In NOVA company, the turnover rate for employee who are fresh graduate was around 18 months until 24 months while the turnover rate for hiring the experienced employee was around 24 months until 36 months. They are resigning mainly because of some reason such as marriage status, children, working-life balance and others."

HR Manager

As to ensure every job position in GBS company has filled, the recruitment will always be conducted from time to time. The HR Manager described that:

"We always hire new employees as to ensure that every job position are filled."

HR Manager

Most of the GBS company have recruitment strategies so that they can fulfil the positions immediately. The recruitment are based on internal or external recruiting methods. The recruitment strategies will be categorized to recruiting intern, fresh graduate or experienced employee. For fresh graduate, they will cooperate with university to hire the fresh graduate. The experience employee are the one who have experienced dealing with the task demanded or having experienced working in other global services companies. One of the HR officer 
stated that finding and recruiting fresh graduate employee sometime will not be easy as the company need to ensure that employees that they hired are having good attitude and behavior.

"We want to hire employees with good attitude and willing to learn."

HR Officer

Meanwhile, the challenges for recruiting experienced employees is related to the higher salary demand. As such, the action of hiring experienced employees will incur certain cost compared to hiring fresh graduate. However, according to the HR Manager, the company need to plan and re-look back at the position that they need to fill in whether it demanded for experienced worker or it can be handled by junior executive. Sometime, the existing employee are given opportunity to upgrade their grade or level. For example:

"I was once a junior officer in this firm for 3 years, then the company offered me to go for a training so that I can upgrade my level to be senior officer and also increase my salary."

Senior Executive

Once they are selected, they will be offered to working with probation. They will be confirmed as employees with or less than 6 months based on their performance. In that period, the new employees will be given graduate training programme including contract role, talent and quickly to home, training make up plan which to build up their right attitude and experience and friendship training to work with buddy and build up their connectivity with colleagues.

"As a new employee here, the company provides us with orientation and training"

Junior Executive

\section{Retention}

In GBS firm, the management provide plenty of benefit to their employees. For example, from the observation in one of the GBS firm, the management has set up one room that was equipped with various facilities for the employees to enjoy and relax. The employees were given flexibility by not having a punch in and out system. One of the statement of the Head Manager stated that:

"In this company, I always encourage my employees to work on flexi hours and we are like a family here. We allow our employees to have a break and enjoy their time. This is because our mission is not having the employees base on full time of working hour, but we focus on the task assigned to the employees must be completed within the stipulated time. The working arrangement will be depends on the employee as long you finish your job"

\section{Head Manager}

"Working in this company, I need to have a night shift due to different time zone with our client's companies. It is quite tough for me as a lady who need to come to work during midnight but I still enjoy it as the management did give a lot of benefit for us who need to work during night shift. We could get parking allowance and also flexi time of working hours."

\section{Executive Officer}

In meantime, the employees in GBS firm are given opportunity to enhance their knowledge and skill by engaging themselves in training or courses. One of the officer did mentioned that: "Working here give me a lot of opportunity to travel around the world. I also had opportunity to join any courses that could help me to improve my skills." 
Apart from that, the most valuable things that employees always think about working in GBS firm is higher amount of salary. According to HR Manager in one of the GBS, the employees enjoy higher increment of salary and bonus each year. From this, it could be seen that the GBS firm provides plenty of opportunity for their employees apart from monetary benefit.

\section{Discussion}

This research use qualitative analysis using in-depth interviews to collect data. From the content analysis of the data, this study found that GBS firm manage their talent based on HRM of planning, recruitment and selection, and retention. This latter finding extends those process as to be specifically related to the operation of global services company.

First, the study found that employees who are recruited by GBS firm are based on internal and external recruiting process. Both of the methods was employed by the GBS firm and deem as the best way of blending the employees capacity and skills with the demand of the job scope required by the customers. Moreover, the selection of GBS employees are based on various tools such as background information, interview process and test (Kinicki \& Williams, 2019). The attitude and behavior become one of the important criteria that HR Manager was looking for a candidate. This is due to the different environment and culture posses by various customers of GBS firm around the globe. In addition, employees in GBS firm must have skills on entertaining their client globally.

Second, the study found that GBS firm used several strategy in retaining their best talent. GBS firm employed various strategies as ways to retain their talented and skilful employees. On this point, employees are given plenty of benefit that not only focus on the monetary benefit only but also employee's self improvement as one of the support for them to enhance their capabilities and skills.

It is clear that GBS firm are deem as international business player and as such they need to manage and retain their talent and workforce strategically. The results indicated that $\mathrm{HR}$ planning, recruitment and selection and retention closely linked to a good HR practices of a GBS firm. This is crucial for GBS firm because their talent and workforce are deem as valuable asset for the firm. In turn, GBS firm must find ways on to retain and transform their talent to be valuable. By having a proper and systematic process of retention, GBS firm could further enhance their talent and workforce in the organization.

\section{Conclusion}

The focal issues of implementing HRM in GBS firm was addressed in this study. First of all, this study has explored the three factors of planning, recruitment and selection, and retention of talent and workforce in GBS company in Malaysia. The first process involved the strategy of the GBS firm to find capable employees to suit with the right position. Next, the recruitment and selection by the GBS firm is crucial as to adhere that GBS firm has find the right and suitable candidates for the available positions. Lastly, the retention aspect may increase the performance and competencies of the GBS firm.

Interesting results were found as showing that managing talent and workforce in GBS company is crucial and highly important. With regard to selecting and recruiting the right candidates for the suitable position through the right process and procedure, reinforced the employees talent. However, the retaining employees are less able to transform their performance if they feel less satisfaction in doing their job. 
It can be concluded from the results of this study that proper planning in human resources management contribute significantly to hiring the right candidate in GBS firm as the working culture and environment of GBS firm is quite unique. The finding of this study will provide new insight for the research on HRM, that is, the adding explanation on the application of HRM practices in the context of GBS firm. In addition, the findings will also provide important enlightenment for practitioners especially the HR Manager in GBS firm.

\section{References}

Barrow, S., \& Mosley, R. (2011). The Employer Brand: Bringing the Best of Brand Management to People at Work, John Wiley \& Sons, England.

Cheese, P. (2008). Driving high performance in the talent-powered organization. Strategic HR Review. 7-4, 25-31.

Cheng, C. C., \& Shiu, E. C. (2015). The inconvenient truth of the relationship between open innovation activities and innovation performance. Management Decision. 53 (3), 625647.

Chesbrough, H. (2003). Open Innovation: The New Imperative for Creating and Profiting from Technology, Harvard Business School Press, Boston, MA.

Eichengreen, B., \& Gupta, P. (2012). The two waves of service sector growth. Nationa Bureau of Economic Research, Cambridge, MA.

Greening, D. W., \& Turban, D. B. (2001). Corporate social performance as a competitive advantage in attracting a quality workforce, Business\& Society. 39 (3), 254-280.

Huggins, R., \& Thompson, P. (2015). Entrepreneurship, innovation and regional growth: a network theory", Small Business Economics. 45 (1), 103-128.

Wei, L. H. (2017). Managing virtual teams for open innovation in Global Business Services industry. Management Decision. 56 (6), 1285-1305.

Lyons, B. D., \& Marler, J. H. (2011). Got image? Examining organizational image in web recruitment", Journal of Managerial Psychology. 26 (1), 58-76.

Manning, S., Larsen, M. M., \& Bharati, P. (2015). Global delivery models: the role of talent, speed and time zones in the global outsourcing industry. Journal of International Business Studies. 46 (7), 850-877.

Michaels, E., Handfield-Jones, H., \& Axelrod, B. (2001). War for Talent (Hardcover), Harvard Business School Press Books, Boston. NST (2019).

Riege, A. M. (2003). Validity and reliability test in case study research: a literature with "hands-on" application for each research phrase. Qualitative Market Research:An International Journal.6 (2), 75-86.

Sako, M. (2015). Outsourcing and offshoring: key trends and issues. Emerging Markets Forum, Washington DC.

Wei, L. H., Thurasamy, R., \& Popa, S. (2018). Managing virtual teams for open innovation in Global Business Services industry. Management Decision, 56(6), 1285-1305.

Wirtz, J., Tuzovic, S., \& Ehret, M. (2015). Global business services: Increasing specialization and integration of the world economy as drivers of economic growth. Journal of Service Management, 26 (4), 565-587. 